\title{
Sickness absence among young employees: trends from 2002 to 2013
}

\author{
Hilla Sumanen, Olli PietiläInen, Jouni Lahti, Eero Lahelma and Ossi Rahkonen \\ Department of Public Health, University of Helsinki, Finland
}

\begin{abstract}
Sickness absence among young employees: trends from 2002 to 2013: Hilla SUMANEN, et al. Department of Public Health, University of Helsinki, Finland-Objectives: Young adults entering employment are a key group in extending work careers, but there is a lack of research on trends in work ability among young employees. Prolonged sickness absence (SA) constitutes a risk for permanent work disability. We examined 12-year trends in SA spells among young female and male municipal employees. Methods: The data were obtained from the employers' registers in the City of Helsinki, Finland. The data included employees aged 18-24, 25-29, 30-34, and 35-54 from 2002 to 2013 (the average number for each year was 31,600 ). Self-certified (1-3 days) and medically certified intermediate (4-14 days) and long (15+ days) SAs were examined. Joinpoint regression models were used to identify major changes in SA trends. Results: Younger employees had more short SAs but fewer long SAs than older employees. During the study period, SAs of almost any length first increased and later decreased among both genders, except for young men. The turning points for short SA were in 2007-2011 among younger and older employees. In intermediate and long SAs the respective turning points were in 2008-2009 and 2005-2009. Women had more SAs in all categories. Conclusions: Age is related to the length of absences. Given the relatively low chronic morbidity among younger employees, it is likely that reasons other than ill health account for increased SA. More evidence on factors behind the changing trends is needed in order to reduce SA and extend the working careers of young people.
\end{abstract}

(J Occup Health 2015; 57: 474-481)

Key words: Female, Male, Morbidity, Occupational health, Sick leave, Young employees

Received Oct 17, 2014; Accepted Jun 18, 2015

Published online in J-STAGE Jul 31, 2015

Correspondence to: H. Sumanen, Department of Public Health, University of Helsinki, PO Box 41 (Mannerheimintie 172), FIN00014 University of Helsinki, Finland (e-mail: hilla. sumanen@helsinki.fi)
Sickness absence (SA) means absence from work due to ill health that affects work ability. It is a medical, psychological, social, and economic phenomenon and is often used as an indicator of employee health ${ }^{1)}$. It imposes considerable direct and indirect costs on the employee and the employer ${ }^{2)}$. Increased SA among younger employees has raised concerns in the Finnish labor-market debate. Young adults entering working life play a key role in extending working careers, and prolonged SA is a challenge in this respect ${ }^{3}$. Previous studies have concentrated on older age groups: thus there is a need to investigate trends and changes in SA in order to plan and evaluate appropriate actions to reduce SA and extend the work careers of young employees.

SA can be divided into shorter and longer periods in accordance with various classifications. A short SA may not be wholly related to ill health but may also reflect coping behavior ${ }^{4}$, and it is sometimes referred to as voluntary or motivational absence ${ }^{5)}$. However, short SAs, especially if they are frequent, also predict longer SA, suggesting a not insignificant effect on health and work ability ${ }^{6}$. Long, medically confirmed $\mathrm{SA}$ is a strong risk factor for permanent work disability $^{3)}$.

Previous studies have shown that SA varies by age $^{7,8)}$, and that young employees have more short SAs than their older counterparts ${ }^{9)}$. It was also found in a Swedish study that young adults aged 18-29 had more self-certified SAs (1-7 days) than their 30-54-year-old counterparts ${ }^{6}$, which reflects the findings of our previous study ${ }^{10}$. Overall, younger employees tend to have fewer long SAs than their older counterparts ${ }^{10)}$.

It is also well established that women have more SAs than men irrespective of length ${ }^{7,10)}$. This higher rate among women has been attributed to different occupations ${ }^{10)}$, psychosocial ${ }^{11)}$ and physical work demands ${ }^{12)}$, working conditions ${ }^{13)}$, and work-family imbalance ${ }^{14)}$. However, according to some findings, the gender divide cannot be attributed to a tendency among women to have a less healthy working envi- 
ronment than men ${ }^{15)}$, and family-related factors also show only weak associations with $\mathrm{SA}^{12)}$. Pregnant women $^{16)}$ and young women with children ${ }^{17)}$ have high SA rates.

Studies on SA among young employees are lacking. In order to address this need, our aim was to investigate 12-year trends in self-certified and medically certified SA among young (less than 35 years old) female and male employees. Older (35-54 years old) employees were used as a reference group. The specific aims were to examine 1) age group differences in trends in short, intermediate, and long SAs and 2) changes in the SA trends among the different age groups from 2002 to 2013.

\section{Material and Methods}

\section{Data}

This study was part of the Helsinki Health Study on health and well-being performed with employees of the City of Helsinki, Finland ${ }^{18)}$. Helsinki is the capital of Finland and has more than 600,000 inhabitants ${ }^{19)}$. The City of Helsinki is the country's largest employer, and its main areas of operation include healthcare, education, social-welfare services, public transport, culture, construction, and technical services. During the study period, the number of all staff was approximately 40,000 and the proportion of women was around $75 \%$ 20,21).

We used City of Helsinki personnel and SA registers to obtain individual-level information on SA and sociodemographic characteristics. The registers cover all employees, their work contracts, and SAs to an accuracy level of one day.

All staff permanently and temporarily employed in the years 2002-2013 and aged 18-24, 25-29, 30-34, and $35-54^{10,22)}$ were included in the analyses (Table 1). Part-time employees, i.e., employees with less than 28 weekly working hours, and those with no registered income (due to leaves of absence or other reasons) were excluded.

We classified SA spells into three lengths: short, 1-3 day SAs, which were self-certified; intermediate, 4-14 day SAs, which were medically certified; and long, 15+ day SAs, which were eligible for sickness allowance paid by the Social Insurance Institution of Finland. We examined annual SAs at the group level ${ }^{10)}$. We combined consecutive and overlapping SAs. All interruptions for reasons other than employee's own illness, such as a child's illness or work injury, were excluded from the analyses.

\section{Statistical methods}

Sickness absence rates and days per 100 personyears for self-certified short (1-3 days), medically certified intermediate (4-14 days), and long (15+ days) SA spells were calculated annually; that is, each year is a cross-section in time. We analyzed women and men separately given the differences in SA trends. All the analyses were conducted by age group for different lengths of SA. Age was adjusted for among the 35-54-year-olds using 2008 data as the standard population. Joinpoint regression modelling ${ }^{23)}$ was used to identify major changes, i.e., turning points in sickness absence trends. In joinpoint models, several different trend lines are connected together at the turning points. The joinpoint modelling starts with a linear trend line, with 0 turning points, and then tests whether there are turning points that are statistically significant and should be added to the model. We specified the maximum number of turning points as two based on visualization of the actual SA trends. The statistical significance of a change in the trend was assessed using a Monte Carlo Permutation method. Annual percentage changes, that is, estimated constant percentage changes per year, were calculated from the joinpoint models for the identified trend periods. Annual percentage changes along with 95\% confidence intervals (CI) are presented for each identified SA trend period. Analyses were conducted using Joinpoint Regression Program version 4.1.124).

\section{Results}

\section{Changes in SA trends among women}

Table 1 presents the descriptive statistics for the years 2002, 2006, 2010, and 2013. Women had more SAs of any length than men. The number of short (1-3 days) SAs (Table 1, Fig. 1) was higher in the younger age groups; the youngest employees had the highest levels, and the oldest employees had the lowest levels. Among the women, short SAs first increased and then decreased during the study period in all age groups. The joinpoint regression models (Table 2, Fig. 1) confirmed the turning points in the trends from 2007 to 2010: they were earlier among the younger women than the older women. Short SAs increased for each age group at the beginning of the study period, the strongest increase $(3.3 \%)$ being among the 25-29 year olds (CI 1.2, 5.5) annually. Short SAs decreased towards the end of the study period in each age group, ending up higher among the 25-29 and 35-54 year olds and at the same level among the 18-24 and 30-34 years olds at the end of the study period compared with the values at the beginning.

The trends in intermediate (4-14 days) SAs (Fig. 2) were very similar in all age groups. The amount of intermediate SAs among the youngest women was considerably higher than that among the older ones and very similar in the two oldest groups. After an initial increase, there was a decreasing trend, the turn- 
Table 1. Descriptive statistics covering employees of the City of Helsinki in 2002, 2006, 2010, and 2013

\begin{tabular}{|c|c|c|c|c|c|c|c|c|}
\hline & \multicolumn{4}{|c|}{ Women } & \multicolumn{4}{|c|}{ Men } \\
\hline & 2002 & 2006 & 2010 & 2013 & 2002 & 2006 & 2010 & 2013 \\
\hline \multicolumn{9}{|l|}{$\mathrm{n}$} \\
\hline Age $18-24$ & 2,083 & 2,118 & 3,038 & 2,947 & 876 & 761 & 1,301 & 1,133 \\
\hline Age $25-29$ & 3,091 & 2,599 & 3,164 & 3,384 & 947 & 908 & 1,113 & 1,102 \\
\hline Age 30-34 & 3,171 & 2,793 & 2,933 & 3,154 & 1,024 & 1,020 & 1,039 & 1,193 \\
\hline Age $35-54$ & 16,049 & 15,446 & 14,663 & 14,378 & 5,406 & 5,151 & 4,829 & 5,038 \\
\hline \multicolumn{9}{|c|}{ Average SA days } \\
\hline Age 18-24 & 17.5 & 19.3 & 18.2 & 17.8 & 11.2 & 11.6 & 11.4 & 10.9 \\
\hline Age $25-29$ & 15.2 & 17.7 & 16.9 & 14.9 & 11.0 & 11.7 & 10.5 & 10.3 \\
\hline Age $30-34$ & 14.5 & 16.3 & 16.9 & 14.9 & 12.4 & 12.7 & 11.6 & 9.9 \\
\hline Age $35-54$ & 17.4 & 19.0 & 18.3 & 17.4 & 14.5 & 15.1 & 13.3 & 12.6 \\
\hline \multicolumn{9}{|l|}{ Have SA \% } \\
\hline Age 18-24 & 64.6 & 62.7 & 63.6 & 62.5 & 47.3 & 45.5 & 48.7 & 47.3 \\
\hline Age $25-29$ & 71.4 & 70.4 & 73.0 & 67.7 & 62.4 & 58.7 & 58.5 & 53.9 \\
\hline Age $30-34$ & 70.5 & 68.1 & 70.9 & 67.9 & 65.1 & 68.5 & 64.4 & 60.4 \\
\hline Age $35-54$ & 73.4 & 75.1 & 77.1 & 74.4 & 60.2 & 61.4 & 62.6 & 63.0 \\
\hline \multicolumn{9}{|c|}{ Permanent workers $\%$} \\
\hline Age 18-24 & 12.5 & 14.1 & 16.9 & 21.8 & 10.5 & 11.3 & 11.3 & 16.3 \\
\hline Age $25-29$ & 42.4 & 43.6 & 44.3 & 49.9 & 43.8 & 38.7 & 43.3 & 46.5 \\
\hline Age $30-34$ & 62.6 & 70.0 & 69.7 & 66.9 & 63.1 & 65.2 & 65.8 & 69.7 \\
\hline Age $35-54$ & 79.6 & 82.6 & 83.7 & 83.8 & 74.0 & 76.8 & 85.2 & 84.8 \\
\hline \multicolumn{9}{|l|}{$1-3$ day $\mathrm{SA}^{*}$} \\
\hline Age 18-24 & 358.4 & 393.2 & 385.5 & 359.2 & 256.8 & 241.2 & 270.3 & 239.5 \\
\hline Age $25-29$ & 255.3 & 276.6 & 290.3 & 260.9 & 203.4 & 204.1 & 211.9 & 184.8 \\
\hline Age 30-34 & 214.5 & 223.0 & 237.6 & 216.5 & 167.9 & 202.9 & 187.6 & 165.8 \\
\hline Age $35-54$ & 183.1 & 199.9 & 224.1 & 204.6 & 125.2 & 135.5 & 151.4 & 138.4 \\
\hline \multicolumn{9}{|l|}{ 4-14 day SA* } \\
\hline Age 18-24 & 112.5 & 108.9 & 110.8 & 100.4 & 66.1 & 54.4 & 67.5 & 60.7 \\
\hline Age $25-29$ & 80.3 & 89.3 & 85.6 & 78.4 & 61.2 & 55.5 & 50.5 & 53.5 \\
\hline Age $30-34$ & 72.1 & 77.3 & 76.3 & 66.5 & 60.1 & 61.9 & 51.3 & 46.6 \\
\hline Age $35-54$ & 71.3 & 76.0 & 78.2 & 69.8 & 60.1 & 58.1 & 52.6 & 50.7 \\
\hline \multicolumn{9}{|l|}{$15+$ day $\mathrm{SA}^{*}$} \\
\hline Age $18-24$ & 11.9 & 17.3 & 14.0 & 15.2 & 8.1 & 10.0 & 7.5 & 9.3 \\
\hline Age $25-29$ & 15.5 & 19.9 & 17.8 & 14.9 & 11.5 & 12.6 & 8.2 & 9.5 \\
\hline Age $30-34$ & 16.3 & 19.8 & 17.9 & 16.7 & 13.6 & 13.2 & 9.7 & 8.5 \\
\hline Age $35-54$ & 22.1 & 23.1 & 20.7 & 20.1 & 18.7 & 18.5 & 15.8 & 13.8 \\
\hline
\end{tabular}

* Sickness absences per 100 person-years.

ing points being in 2009 in all age groups (Table 2, Fig. 2). The biggest annual increase between 2002 and $2009(3.2 \%)$ was among the 25-29 year olds (CI $0.6,5.9)$. The strongest annual decrease from 2009 to $2013(6.3 \%)$, in turn, was among the 30-34 year olds (CI -10.3, -2.0). Women had slightly fewer intermediate SAs among the 18-24 and 30-34 year olds and the same level of intermediate SAs among the 25-29 and 35-54 year olds at the end of the study period compared with the values at the beginning.

The younger women had fewer long $(15+$ days $)$ SAs than the older ones (Table 1, Fig. 3), the numbers increasing in each age group from 2002 to 2005 and decreasing until 2013, except for the 25-29 year olds
(Table 2, Fig. 3). The biggest annual increase between 2002 and 2005 (15.4\%) was among the 18-24 year olds (CI 1.1, 31.8), whereas the most rapid annual decrease from 2005 to $2013(3.2 \%)$ was among the 30-34 year olds (CI -4.8, -1.6). In 2013, women had considerably more long SAs among the 18-24 year olds, the same level of long SAs among the 30-34 year olds, and slightly fewer long SAs among the 25-29 and 35-54 year olds compared with the values in 2002.

\section{Changes in SA trends among men}

The number of short (1-3 days) SAs (Table 1, Fig. 1) was higher in men in the younger age groups, 
Table 2. Identified periods (turning points) in sickness absence spells by age group, 2002-2013

\begin{tabular}{|c|c|c|c|c|}
\hline & \multicolumn{2}{|r|}{ Women } & \multicolumn{2}{|r|}{ Men } \\
\hline & $\begin{array}{l}\text { Identified periods } \\
\text { (turning points) }\end{array}$ & $\begin{array}{l}\text { Annual percentage change } \\
\text { in the identified period } \\
(95 \% \mathrm{CI})\end{array}$ & $\begin{array}{l}\text { Identified periods } \\
\text { (turning points) }\end{array}$ & $\begin{array}{l}\text { Annual percentage change } \\
\text { for the identified period } \\
(95 \% \mathrm{CI})\end{array}$ \\
\hline \multicolumn{5}{|c|}{$1-3$ day $\mathrm{SA}^{*}$} \\
\hline Age $18-24$ & $\begin{array}{l}2002-2007 \\
2007-2013\end{array}$ & $\begin{aligned} 2.5 & (-0.7,5.9) \\
-2.1 & (-4.1,0.1)\end{aligned}$ & 2002-2013 & $0.2(-1.2,1.7)$ \\
\hline Age $25-29$ & $\begin{array}{l}2002-2008 \\
2008-2013\end{array}$ & $\begin{aligned} 3.3 & (1.2,5.5) \\
-2.4 & (-4.9,0.2)\end{aligned}$ & $\begin{array}{l}2002-2009 \\
2009-2013\end{array}$ & $\begin{aligned} 1.2 & (0.3,2.0) \\
-3.8 & (-5.6,-2.0)\end{aligned}$ \\
\hline Age $30-34$ & $\begin{array}{l}2002-2010 \\
2010-2013\end{array}$ & $\begin{aligned} 1.7 & (0.4,2.9) \\
-2.8 & (-8.1,2.8)\end{aligned}$ & $\begin{array}{l}2002-2007 \\
2007-2013\end{array}$ & $\begin{aligned} 4.7 & (1.1,8.5) \\
-3.5 & (-5.9,-1.0)\end{aligned}$ \\
\hline Age $35-54$ & $\begin{array}{l}2002-2010 \\
2010-2013\end{array}$ & $\begin{aligned} 2.6 & (1.9,3.2) \\
-3.3 & (-6.0,-0.5)\end{aligned}$ & $\begin{array}{l}2002-2011 \\
2011-2013\end{array}$ & $\begin{aligned} 2.1 & (1.2,2.9) \\
-5.6 & (-13.6,3.2)\end{aligned}$ \\
\hline \multicolumn{5}{|c|}{ 4-14 day SA* } \\
\hline Age 18-24 & $\begin{array}{l}2002-2009 \\
2009-2013\end{array}$ & $\begin{aligned} 1.6 & (0.0,3.3) \\
-4.1 & (-7.3,-0.7)\end{aligned}$ & $2002-2013$ & $0.0(-2.3,2.4)$ \\
\hline Age $25-29$ & $\begin{array}{l}2002-2009 \\
2009-2013\end{array}$ & $\begin{aligned} 3.2 & (0.6,5.9) \\
-5.7 & (-11.1,0.0)\end{aligned}$ & $2002-2013$ & $-2.2(-4.1,0.3)$ \\
\hline Age $30-34$ & $\begin{array}{l}2002-2009 \\
2009-2013\end{array}$ & $\begin{aligned} 2.1 & (0.3,4.0) \\
-6.3 & (-10.3,-2.0)\end{aligned}$ & $\begin{array}{l}2002-2008 \\
2008-2013\end{array}$ & $\begin{aligned} 0.7 & (-2.2,3.6) \\
-7.0 & (-10.6,-3.3)\end{aligned}$ \\
\hline Age $35-54$ & $\begin{array}{l}2002-2009 \\
2009-2013\end{array}$ & $\begin{aligned} 2.6 & (1.0,4.2) \\
-4.5 & (-8.1,-0.7)\end{aligned}$ & $\begin{array}{l}2002-2009 \\
2009-2013\end{array}$ & $\begin{array}{ll}-0.3 & (-1.6,1.0) \\
-4.2 & (-7.4,-0.9)\end{array}$ \\
\hline \multicolumn{5}{|c|}{$15+$ day $\mathrm{SA}^{*}$} \\
\hline Age $18-24$ & $\begin{array}{l}2002-2005 \\
2005-2013\end{array}$ & $\begin{array}{l}15.4(1.1,31.8) \\
-2.5(-4.7,-0.2)\end{array}$ & $2002-2013$ & $1.5(-1.2,4.2)$ \\
\hline Age $25-29$ & $\begin{array}{l}2002-2009 \\
2009-2013\end{array}$ & $\begin{aligned} 2.2 & (-1.3,5.9) \\
-6.4 & (-13.5,1.4)\end{aligned}$ & $2002-2013$ & $-3.4(-5.9,-0.7)$ \\
\hline Age $30-34$ & $\begin{array}{l}2002-2005 \\
2005-2013\end{array}$ & $\begin{aligned} 8.7 & (0.5,17.6) \\
-3.2 & (-4.8,-1.6)\end{aligned}$ & $\begin{array}{l}2002-2007 \\
2007-2013\end{array}$ & $\begin{aligned} 1.8 & (-4.8,9.0) \\
-10.3 & (-15.2,-5.1)\end{aligned}$ \\
\hline Age $35-54$ & $\begin{array}{l}2002-2005 \\
2005-2013\end{array}$ & $\begin{aligned} 2.5 & (-1.9,7.2) \\
-2.4 & (-3.4,-1.4)\end{aligned}$ & $\begin{array}{l}2002-2005 \\
2005-2013\end{array}$ & $\begin{aligned} 5.3 & (-2.5,13.7) \\
-5.4 & (-7.1,-3.7)\end{aligned}$ \\
\hline
\end{tabular}

* Sickness absences per 100 person-years.

and this was similar to the results for the women: there was first an increase and then a decrease, except for the youngest group. The turning points in the trends (Table 2, Fig. 1) varied from 2007-2009 among the younger men to 2011 among the oldest men. The 30-34 year olds had the highest annual increase $(4.7 \%)$ at the beginning of the study period (CI 1.1, 8.5). The number of short SAs decreased towards the end of the study period in the three oldest age groups, ending up lower among the 25-29 year olds, at the same level among the 30-34 year olds and slightly higher among the 35-54 year olds at the end compared with the values at the beginning.

In contrast to the results for the women, the numbers of intermediate (4-14 days) SAs among the men (Table 1, Fig. 2) were fairly even across the age groups. There was an increase among the 30-34 year olds until 2008, followed by a rapid decrease from
2008 to 2013 (-7.0, CI -10.6, -3.3) (Table 2, Fig. 2). The number of intermediate SAs was lower in 2013 than in 2002 in all groups (Table 1).

The three youngest age groups differed from the oldest in terms of long SAs (Table 1, Fig. 3), the number of which was higher among the older men. The number of long SAs increased in the two oldest groups from 2002 to 2005-2007, followed by a decrease until 2013 (Table 2, Fig. 3). The annual decrease between 2007 and $2013(-10.3 \%)$ was more rapid among the 30-34 year olds (CI -15.2, -5.1). Long SAs decreased (-3.4\%) annually among 25-29 year olds from 2002 to 2013 (CI -5.9, -0.7). The number of long SAs in the three oldest age groups was at considerably lower at the end of the study period than at the beginning. 

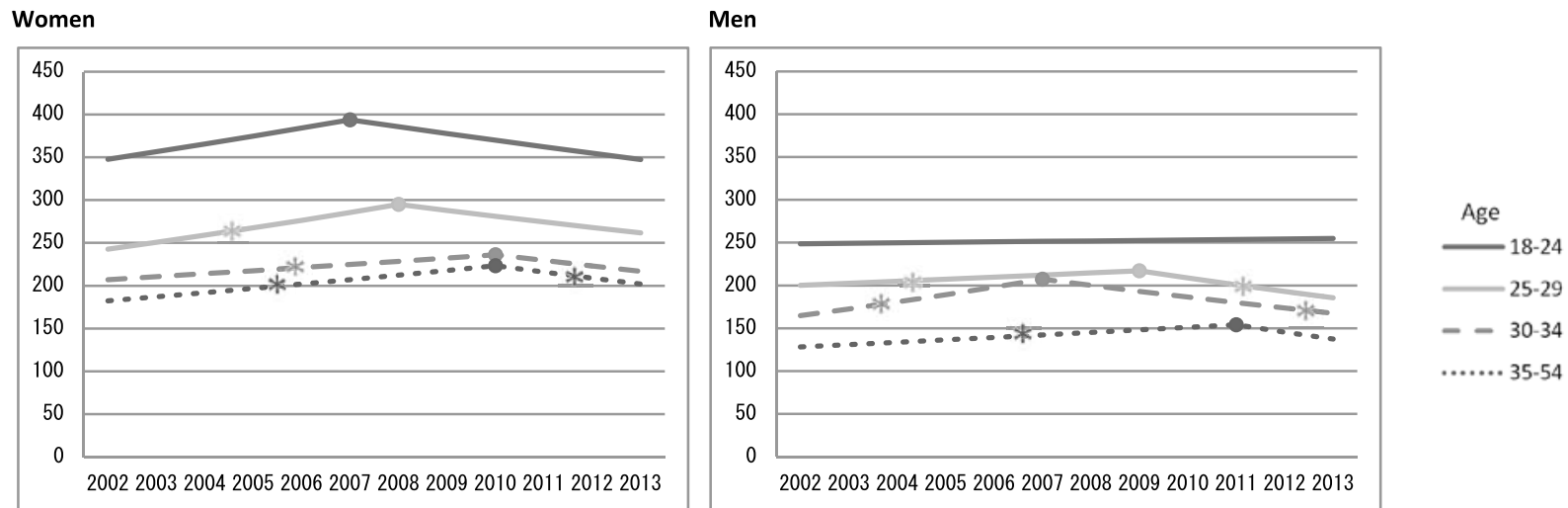

Fig. 1. Joinpoint regression-modelled short (1-3 days) sickness absence spells by gender for 2002-2013 per 100 personyears. $* p<0.05$.
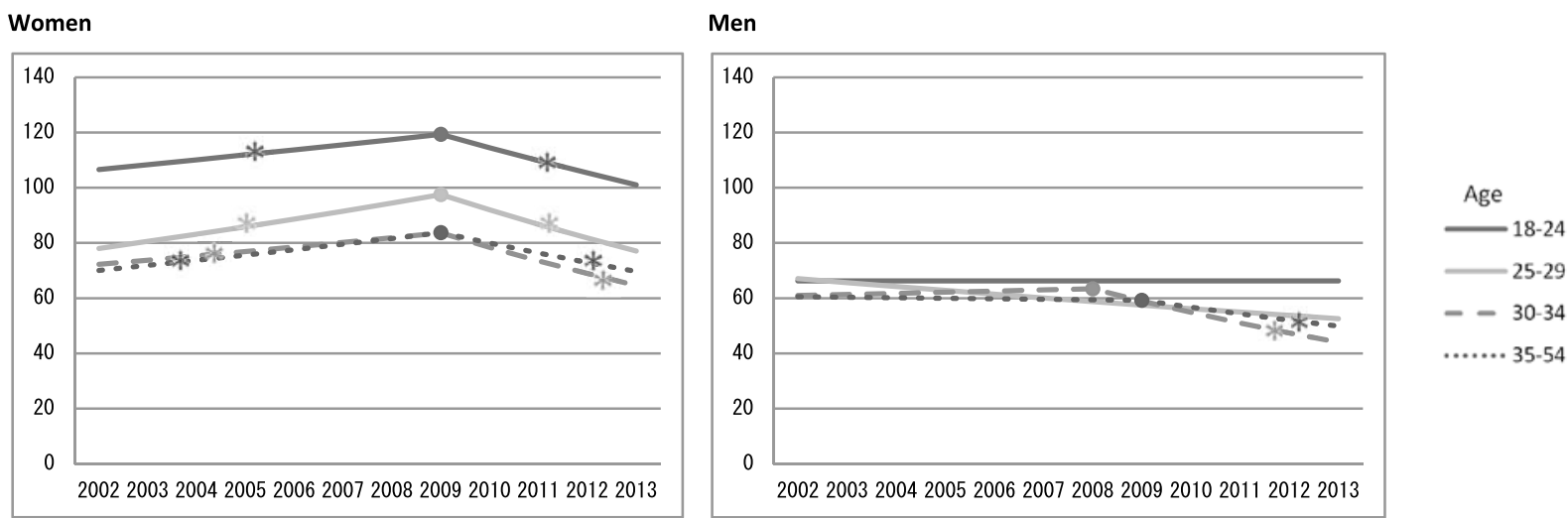

Fig. 2. Joinpoint regression-modelled intermediate (4-14 days) sickness absence spells by gender for 2002-2013 per 100 person-years * $p<0.05$.
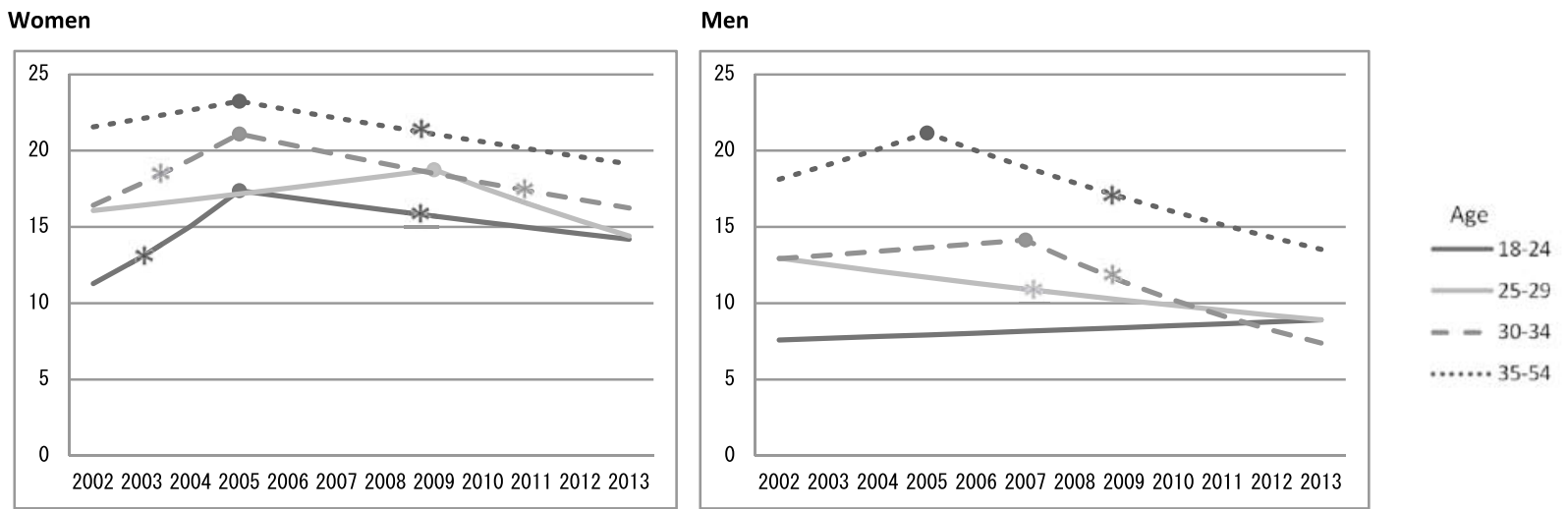

Fig. 3. Joinpoint regression-modelled long (15+ days) sickness absence spells by gender for 2002-2013 per 100 personyears. $* p<0.05$.

\section{Discussion}

This study examined trends in sickness absence spells of various lengths among younger female and male municipal employees from 2002 to 2013, as compared with their older counterparts. The main results were as follows. 1) The numbers of short and intermediate SAs were higher and that of long SAs was lower among the younger employees compared with their older counterparts. 2) During the study 
period, the differences between age groups remained broadly similar for short SAs among both genders and for intermediate SAs among women, increased for intermediate SAs among men, and decreased for long SAs among both genders. 3) SAs of almost any length among both women and men first increased and then decreased during the study period. 4) Throughout the study period, women had more SAs of any length than men.

Our results revealed higher numbers of short SAs among the younger employees than the older employees, which is in line with previous findings ${ }^{6)}$. This could be related to the more rapid recovery from infectious diseases among young people, for example, but in that case, the number of intermediate SAs should be much lower than among older employees. It has been suggested that short SAs might be related to motivational issues ${ }^{5)}$ and not only to ill health. For example, younger employees may prefer leisure time to paid work ${ }^{25}$. It has also been suggested that younger employees might stay away from work due to minor health problems more readily than older employees and therefore have higher levels of short $\mathrm{SA}^{9)}$. In our data, the educational and occupational class distributions remained relatively similar during the study period, indicating that changes and differences in SA among the different age groups might not be related to socioeconomic position. There were also no substantial changes in the social-benefit system in Finland during the period of 2002 to 2013. Employees receive their full salary during SAs of less than 10 working days (14 days including weekends); thus a reduction in earnings is unlikely to affect short absences. The higher number of long SAs among older employees than among younger ones is in line with the results of previous studies ${ }^{10)}$, as sickness increases with age ${ }^{7)}$. Women had more SA than men in all age groups irrespective of length, as has also been found in previous studies ${ }^{7,10)}$.

Employees with permanent and nonpermanent contracts were all included in our analyses. Among the young employees, the percentage of people with a permanent contract (Table 1) varied during the study period, from 11 to $22 \%$ among the 18-24 year olds and from 39 to $50 \%$ among the 25-29 year olds. More women than men in these two youngest age groups had permanent job contracts. Of the 30-34 and 35-54 year olds, 63-70\% and $74-85 \%$, respectively, had permanent contracts. According to the results of a Swedish study, women with nonpermanent contracts had significantly lower numbers of short and long SAs than permanent employees, but permanence did not affect SAs among men ${ }^{26)}$. We were unable to investigate the effect of job permanence on SAs because of the small numbers of permanent employees in the younger age groups.

Finland went into an economic downturn in 2008, and by that end of the year, there was a perceived increase in job insecurity ${ }^{27}$. Studies have shown that downsizing reduces non-health-related absences, but increases ill health and long $\mathrm{SAs}^{28)}$. Job insecurity can lead to increasing SA because of the stressor effect ${ }^{29)}$, but it can also lead to increasing sickness "presenteeism"30). We identified clear turning points in most of the SA trends, which in the case of short and intermediate SAs in particular were located between the years 2007 and 2010. It is possible that the decreasing trend is related to the economic situation. The turning points occurred earlier in the case of long SAs, and the absolute trends (Table 1) show that long SAs increased among the youngest women and men and also among 25-29 year old men from 2010 to 2013. Many people in these groups have nonpermanent jobs, and job insecurity may have a detrimental effect on health.

The City of Helsinki offers similar occupational health services to all its employees, but a specific preventive focus on working communities rather than individuals started in 200720). The preventive measures include support for these communities, and comprehensive occupational health services for superiors aiming to improve their work ability and potential to support their subordinates. A good relationship between superiors and subordinates helps to reduce $\mathrm{SA}^{31)}$. The City of Helsinki also introduced a model requiring superiors to discuss $\mathrm{SA}$ with their subordinates when the number of days of absence reaches a certain level $^{20)}$. These measures may also have influenced the SA levels and could explain some of the decrease in intermediate and long SAs after 2007.

Joinpoint modelling enabled us to identify changes in the recent SA trends, which is important especially in terms of designing and evaluating workplace measures aiming to reduce SA in different age groups. Based on our results, although young employees have less chronic diseases, their SA levels suggest a need for paying attention to their health and lifestyles, which might be connected to their SA behaviors. Measures undertaken by employers and occupational health care services are key ways of improving health and reducing SA. Towards the end of our study period, SA among younger employees decreased, which is a positive direction and sign. However, further measures are needed to prevent possible increase in SA in the future. SA-related behaviors may also remain as younger employees get older. This would increase the burden of SA for employees and employers, particularly as health and functioning deteriorate with increasing age. Monitoring future trends in SA also provides important information for evaluating prior 
preventive measures and suggesting further efficient measures to reduce SA among young employees.

\section{Methodological considerations}

This study was based on extensive SA registers held by the employer, providing a reliable and comprehensive data source. However, the study population included more women than men, which is typical in the Finnish municipal sector ${ }^{12}$. In the case of younger men, the small number of participants affected the statistical power in the analysis of the turning points in SA trends. We lack diagnostic information, which is a limitation especially in the case of young female workers, who in previous studies have been shown to have more pregnancy-related SAs than other women ${ }^{16)}$. However, pregnancy-related absences are usually long$\mathrm{er}^{16)}$ and therefore do not explain the high number of short SAs among younger women. The participants in our study were municipal employees from the City of Helsinki, the largest employer in Finland. Our results can be generalized with caution to the Finnish municipal sector, but not to the labor force in general.

\section{Conclusions}

Reducing both shorter and longer sickness absences is in the interests of the employer and the employee, as well as occupational healthcare services. Short SAs may cause harm to employers due to difficulties in arranging cover at short notice and leaving work undone $^{32)}$. Long and frequent SAs have a particularly high economic price ${ }^{32}$. Preventive measures should be focused especially on short and intermediate SAs among younger employees and long SAs among older employees. However, the number of long SAs in the youngest women is now higher than at the beginning of the 2000s. There is a need to extend work careers; thus investments in employee health and work ability are needed in the early stages, before illnesses begin to appear.

\section{References}

1) Marmot M, Feeney A, Shipley M, North F, Syme SL. Sickness absence as a measure of health status and functioning: from the UK Whitehall II study. J Epidemiol Community Health 1995; 49: 124-30.

2) Feeney A, North F, Head J, Canner R, Marmot M. Socioeconomic and sex differentials in reason for sickness absence from the Whitehall II Study. Occup Environ Med 1998; 55: 91-8.

3) Koopmans PC, Roelen CA, Groothoff JW. Frequent and long-term absence as a risk factor for work disability and job termination among employees in the private sector. Occup Environ Med 2008; 65: 494-9.

4) Verhaeghe R, Mak R, van Maele G, Kornitzer M, de Backer G. Job stress among middle-aged health care workers and its relation to sickness absence. Stress and Health 2003; 19: 265-74.

5) Vahtera J, Virtanen P, Kivimäki M, Pentti J. Workplace as an origin of health inequalities. J Epidemiol Community Health 1999; 53: 399-407.

6) Hultin H, Lindholm C, Malfert M, Moller J. Shortterm sick leave and future risk of sickness absence and unemployment - the impact of health status. BMC Public Health 2012; 12: 861-8.

7) Allebeck P, Mastekaasa A. Swedish Council on Technology Assessment in Health Care (SBU). Chapter 5. Risk factors for sick leave-general studies. Scand J Public Health Suppl 2004; 63: 49-108.

8) Krane L, Johnsen R, Fleten N, et al. Sickness absence patterns and trends in the health care sector. Hum Resour Health 2014; 12: 37-44.

9) Taimela S, Läärä E, Malmivaara A, et al. Selfreported health problems and sickness absence in different age groups predominantly engaged in physical work. Occup Environ Med 2007; 64: 739-46.

10) Laaksonen M, Mastekaasa A, Martikainen P, Rahkonen O, Piha K, Lahelma E. Gender differences in sickness absence - the contribution of occupation and workplace. Scand J Work Environ Health 2010; 36: 394-403.

11) Casini A, Godin I, Clays E, Kittel F. Gender difference in sickness absence from work: a multiple mediation analysis of psychosocial factors. Eur $\mathrm{J}$ Public Health 2013; 23: 635-42.

12) Laaksonen M, Martikainen P, Rahkonen O, Lahelma E. Explanations for gender differences in sickness absence: evidence from middle-aged municipal employees from Finland. Occup Environ Med 2008; 65: $325-30$.

13) Laaksonen M, Piha K, Rahkonen O, Martikainen P, Lahelma E. Explaining occupational class differences in sickness absence: results from middleaged municipal employees. J Epidemiol Community Health 2010; 64: 802-7.

14) Lidwall U, Marklund S, Voss M. Work-family interference and long-term sickness absence: a longitudinal cohort study. Eur J Public Health 2010; 20: 676-81.

15) Smeby L, Bruunsgaard D, Claussen B. Sickness absence: could gender divine be explained by occupation, income, mental distress and health? Scand J Public Health 2009; 37: 674-81.

16) Ariansen AM, Mykletun A. Does postponement of first pregnancy increase gender differences in sickness absence? A register based analysis of norwegian employees in 1993-2007. PLoS One 2014; 9: e93006.

17) Åkerlind I, Alexanderson K, Hensing G, et al. Sex differences in sickness absence in relation to parental status. Scand J Soc Med 1996; 24: 27-35.

18) Lahelma E, Aittomäki $A$, Laaksonen $M$, et al. Cohort profile: the Helsinki Health Study. Int J Epidemiol 2013; 42: 722-30.

19) City of Helsinki Urban Facts. Statistical Yearbook of Helsinki 2014. 
20) City of Helsinki. Staff Report 2007 (in Finnish).

21) City of Helsinki. Staff Report 2013 (in Finnish).

22) Social Insurance Institution. Sickness allowance: Number of recipients and allowances paid out. [Online]. 2014 [cited 2015 Mar 5]; Available from: URL: http://raportit.kela.fi/ibi_apps/WFServlet?IBIF_ ex=NIT098AL\&YKIELI=E

23) Kim HJ, Fay MP, Feuer EJ, Midthune DN. Permutation tests for joinpoint regression with applications to cancer rates. Stat Med 2000; 19: 335-51. Erratum in: Stat Med 2001; 20: 655.

24) Joinpoint Regression Program, Version 4.1.1 - August 2014; Statistical Methodology and Applications Branch, Surveillance Research Program, National Cancer Institute.

25) Sheahan P. Generation Y: Thriving and Surviving with Generation Y at Work. Hardie Grant Books. 2005.

26) Khan J, Rehnberg C. Perceived job security and sickness absence: a study on moral hazard. Eur $\mathbf{J}$ Health Econ 2009; 10: 421-8.

27) Statistics Finland. Consumer survey 2008. [Online].
2009 [cited 2014 Aug 18]; Available from: URL: http://www.stat.fi/til/kbar/2008/index_en.html

28) Blekesaune M. Job insecurity and sickness absence: correlations between attrition and absence in 36 occupational groups. Scand J Public Health 2012; 40: 668-73.

29) Vahtera J, Kivimäki M, Pentti J. Effect of organisational downsizing on health of employees. Lancet 1997; 350: 1124-8.

30) Heponiemi T, Elovainio $M$, Pentti $J$, et al. Association of contractual and subjective job insecurity with sickness presenteeism among public sector employees. J Occup Environ Med 2010; 52: 830-5.

31) Stoetzer U, Bergman P, Åborg C, et al. Organizational factors related to low levels of sickness absence in a representative set of Swedish companies. Work 2014; 47: 193-205.

32) Roelen CA, Heymans MW, Twisk JW, et al. Updating and prospective validation of a prognostic model for high sickness absence. Int Arch Occup Environ Health. [published online ahead of print March 25, 2014]. (doi:10.1007/s00420-014-0942-9). 